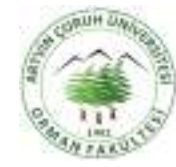

\title{
Şaşırtmanın Toros sedirinde fidan morfoloji ve kalitesine etkisi
}

\section{Influence of transplanting on seedling morphology and quality in Taurus cedar}

\section{Yunus ESER}

Isparta Uygulamalı Bilimler Üniversitesi, Atabey Meslek Yüksekokulu, Atabey, ISPARTA

\section{Eser Bilgisi / Article Info}

Araştırma makalesi / Research article DOI: 10.17474/artvinofd.855865

Sorumlu yazar / Corresponding author Yunus ESER

e-mail: yunuseser@isparta.edu.tr

Geliş tarihi / Received

07.01.2021

Düzeltme tarihi / Received in revised form

11.02.2021

Kabul Tarihi / Accepted

12.02.2021

Elektronik erişim / Online available

12.05.2021

Anahtar kelimeler:

Ayırma

Fidan

Fidanlık

Kök boğazı çapı

Keywords:

Discriminant

Seedling

Nursery

Root collar diameter

\begin{abstract}
Özet
Isparta-Eğirdir Orman Fidanlığında yetiştirilen iki yaşlı şaşırtılmış (1+1) tüplü ve şaşırtılmamış $(2+0)$ çıplak köklü Toros sediri (Cedrus libani A. Rich.) fidanları üzerinde gerçekleştirilen bu çalışmada, şaşırtmanın fidan morfoloji ve kalitesine olan etkisinin, fidan boyu ve kök boğazı çapı bağlamında belirlenmesi amaçlanmıştır. Çalışma sonucunda; şaşırtılmış fidanlar şaşırtılmamış fidanlara göre, boy için yaklaşık \%16 (17.51 cm ve $15.09 \mathrm{~cm})$, kök boğazı çapı için ise \%45 (5.33 mm ve $3.67 \mathrm{~mm})$ daha yüksek büyüme performansı göstermiştir. Fidan boyu ve kök boğazı çapı değerleri bakımından şaşırtılmış ve şaşırtılmamış fidanlar arasında anlamlı $(p \leq 0.05)$ farklııklar belirlenmiştir. Türk Standartları Enstitüsü (TSE) fidan kalite sınıflarına göre, şaşırtılmış ve şaşırtılmamış fidanların tamamı kök boğazı çapı bakımından kaliteli fidan sınıfında yer alırken, boy bakımından dikime elverişsiz fidan şaşırtma uygulanmamış fidanlarda \%4 oranında belirlenmiştir. Uygulanan Ayırma (Diskriminant) analizi sonucunda; TSE kalite sınıflarının fidan boyu bakımından, şaşırtılmış fidanlar için \%98, şaşırtılmamış fidanlar için \%92 ve her iki işlem için ise \%69 oranında başarılı olduğu ortaya çıkmıştır. Korelasyon analizi sonucunda, şaşırtılmış işlemlerin tamamına ait fidanlarda fidan boyu ile kök boğazı çapı arasında istatistiksel bakımdan anlamlı $(p \leq 0.05)$ pozitif ilişkiler belirlenirken, şaşırtılmamış fidanlarda ise anlamlı ( $p>0.05)$ bir ilişki belirlenememiştir. Çalışma sonucunda, şaşırtma uygulamasının fidan morfoloji ve kalitesini olumlu yönde etkilediği ortaya çıkmıştır.
\end{abstract}

\begin{abstract}
This study was carried out based on seedling height and root-collar diameter in transplanted $(1+1)$ containerized and untransplanted ( $2+0)$ bare-root seedlings of Taurus cedar (Cedrus libani A. Rich) to estimate influence of the treatments on seedling quality and morphology. Results of the study showed that transplanted seedlings showed higher $16 \%(17.51 \mathrm{~cm}$ and $15.09 \mathrm{~cm})$ for height and $45 \%(5.33$ $\mathrm{mm}$ and $3.67 \mathrm{~mm}$ ) for root-collar diameter performance than untransplanted seedlings. Significant $(p<0.05)$ differences were found between transplanted and untransplanted seedlings for the characteristics. All transplanted and untransplanted seedlings were in quality class for root-collar diameter according to quality classes of Turkish Standard Institute, while cull seedlings were only in untransplanted seedlings as 4\%. Quality classes of Turkish Standard Institute were suitable $98 \%, 92 \%$ and $69 \%$ for transplanted and untransplanted seedlings, and for both treatments, respectively. There were positive and significant $(p<0.05)$ relations between seedling height and root-collar diameter in transplanted and both treatments, while it was opposite for untransplanted seedlings $(p>0.05)$. Results of the study showed that transplanting treatment had positive effect on seedling quality and morphology in the species.
\end{abstract}

\section{Giriş}

Ülkemizde son yayımlanan orman istatistiklerine göre çalışmaya konu Toros sediri (Cedrus libani A.Rich.), 252.590 ha normal kapalı (\%52) ve 235.229 ha boşluklu kapalı olmak üzere 487819 ha orman alanını kaplamaktadır. Bu yayııış alanı, 13.08 milyon ha'ı normal kapalı olan 22.74 milyon ha büyüklüğündeki Türkiye ormanlarının \%2.1'ini oluşturmaktadır (OGM 2020a). Toros sediri, ülkemiz ormanlarındaki \%2.1'lik yayılış alanına rağmen, değerli odunu, değişik yetişme ortamlarına uyum sağlayabilme yeteneği, park ve bahçelerdeki geniş kullanımı, sosyo-kültürel önemi ve
Boydak ve Çalıkoğlu (2008) tarafından belirtilen 500.000 ha'ın üzerindeki potansiyel yayılış alanı nedeniyle ülkemiz ormancılı̆̆ının önemli ağaç türlerinden biridir.

Ayan ve ark. (2017) tarafından gerçekleştirilmiş olan bir çalışmada, Toros sedirinin, Türkiye'de Anadolu karaçamından (Pinus nigra Arnold. subsp. pallasiana Lamb. Holmboe) sonra ağaçlandırma çalışmalarında en çok tercih edilen ve plastitesi yüksek bir tür olduğu ifade edilmektedir. Ayrıca; türün mevcut ağaçlandırma sahaları iklim tipi açısından değerlendirildiğinde ise; De Martonne (1942)'e göre; "Step-nemli arası", "Yarı nemli" ve "Stepyarı kurak" olan üç iklim tipinde; Erinç (1965)'e göre; 
"Nemli", "Yarı nemli" ve "Step-yarı kurak" iklim tiplerine; Aydeniz (1985)'e göre ise "Kurak", "Yarı kurak", "Nemli" ve "Yarı nemli" iklim tiplerine uyum gösterebildiği ve dolayısıyla türün adaptasyon yeteneğinin uygun popülasyon seçimi ve kullanımı ile değişen iklim şartlarına karşı anahtar bir tür olarak kullanılabileceği belirtilmektedir. Gerek bu nedenlerle ve gerekse türün $\% 48^{\prime}$ lik boşluklu kapalı vasıftaki orman alanı sebebiyle, kaliteli kitlesel fidan üretimi ve bu fidan materyallerini kullanarak ağaçlandırma çalışmalarının gerçekleştirilmesi sedir türünde silvikültürel açıdan oldukça önemlidir.

Orman Genel Müdürlüğü tarafından, 2005-2019 yılları arasında uygulanan "Sedir Ormanlarının Rehabilitasyonu Eylem Planı" ile 160.683 hektar alan rehabilite edilmiştir (OGM 2020b). Gerek rehabilitasyon ve gerekse ağaçlandırma uygulamalarının başarısında, saha hazırlığı ve bakımı, iklim, edafik faktörler, yükselti ile tohum özellikleri, ağaç türü, fidan tipi, yaşı ve kalitesi gibi birçok çevresel ve biyolojik faktörler rol oynamaktadır. Ağaçlandırma çalışmalarının başarısında önemli rol oynayan bu faktörlerden olan fidan morfoloji ve kalitesi üzerine Toros sedirinde çalışmalar gerçekleştirilmiş olmasına karşın (Eler ve ark. 1993, Demirci ve Bilir 2001, Yer ve Ayan 2011, Bilir ve Çetinkaya 2018, Çetinkaya ve Bilir 2019), türde şaşırtma veya şaşırtma yerine geçebilen, ekim sıklığı, seyreltme gibi işlemlerin fidan morfoloji ve kalitesine olan etkisine yönelik tarafımızca az sayıda çalışmaya rastlanılmıştır (Çatal 2002, Yıldız 2005, Kayadibi 2011, Güner ve ark. 2018). Bu çalışmalarda da, şaşırtmanın fidan morfoloji ve kalitesi üzerine olan etkileri doğrudan incelenmemiştir.
Yukarıda kısaca açıklanan bilgiler ışığında bu çalışmada, Eğirdir Orman Fidanlığında yetiştirilen iki yaşı şaşırtıımış ve şaşırtılmamış Toros sediri fidanları, fidan boyu ve kök boğazı çapı bağlamında irdelenerek, şaşırtmanın fidan morfoloji ve kalitesine olan etkisi belirlenmeye çalışılmıştır. Çalışma sonuçlarıyla türün fidanlık tekniği, ağaçlandırma ve diğer ormancılık uygulamalarına katkı sağlanması amaçlanmıştır.

\section{MATERYAL ve YÖNTEM}

Çalışmada kullanılan $1+1$ yaşlı şaşırtılmış tüplü ve şaşırtılmamış 2+0 yaşlı çıplak köklü Toros sediri fidanları, Eğirdir Orman Fidanlığında ( $37^{\circ} 53^{\prime}$ Kuzey enlemi, $30^{\circ} 52^{\prime}$ doğu boylamı, ortalama 926 metre yükseltili, batı bakılı) yetiştirilen, Isparta-Kapıdağ tohum meşceresi orijinli (38 $05^{\prime} 23^{\prime \prime}$ Kuzey enlemi, 3042'20" doğu boylamı, ortalama 1500 metre yükseltili) fidanlardan örneklenmiştir (Şekil 1).

Türün Eğirdir Orman Fidanlığında yetiştirilen ve uygulamadaki dikime uygun yaştan (Anonim 1986) rastgele örneklenen ve birinci vejetasyon dönemi sonunda şaşırtılmış $1+1$ yaşlı tüplü (ŞT) ve 2+0 yaşlı çıplak köklü (ÇK) fidanlarında, 2020 yılı büyüme dönemi sonunda; $0.1 \mathrm{~cm}$ hassasiyetle fidan boyu (FB) ve $0.01 \mathrm{~mm}$ hassasiyetle kök boğazı çapı (KBÇ) ölçümü gerçekleştirilmiş (Şekil 2) ve bu çalışmada şaşırtılmış ve şaşırtılmamış fidanlar işlem olarak ifade edilmiştir.

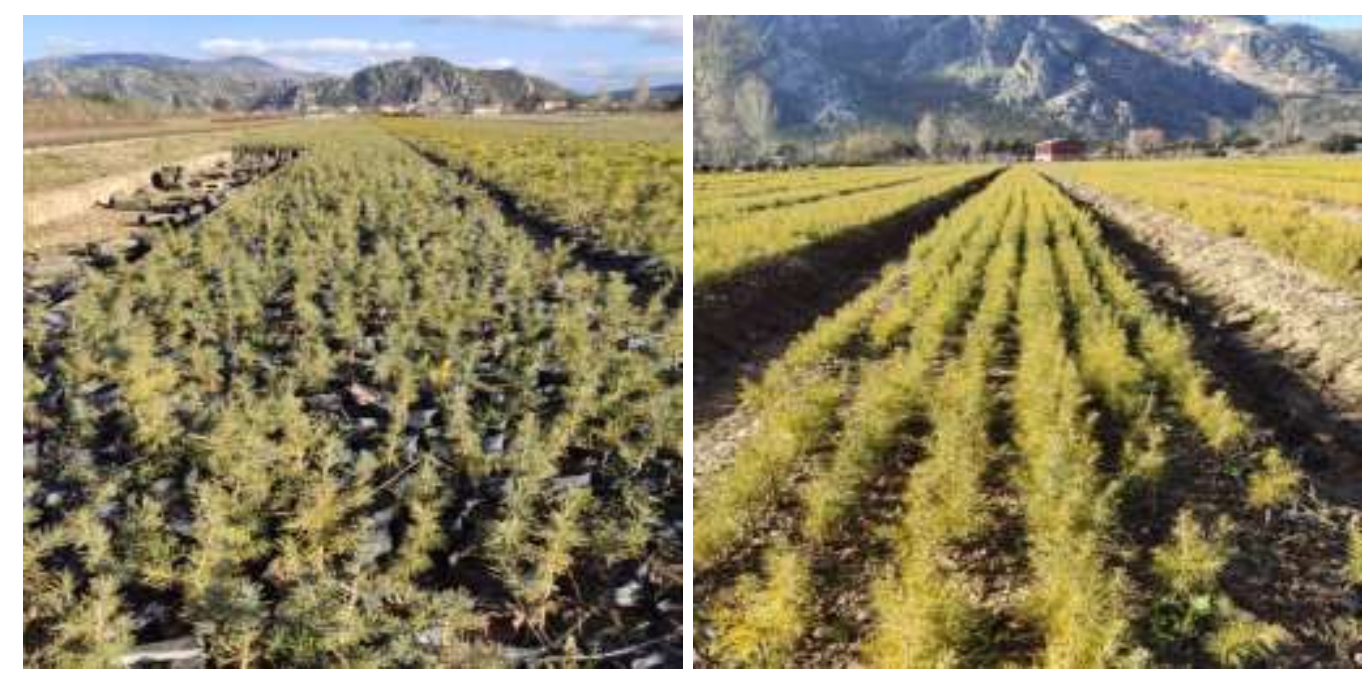

Şekil 1. Çalışmada örneklenen şaşırtılmış ve şaşırtılmamış fidanlar 


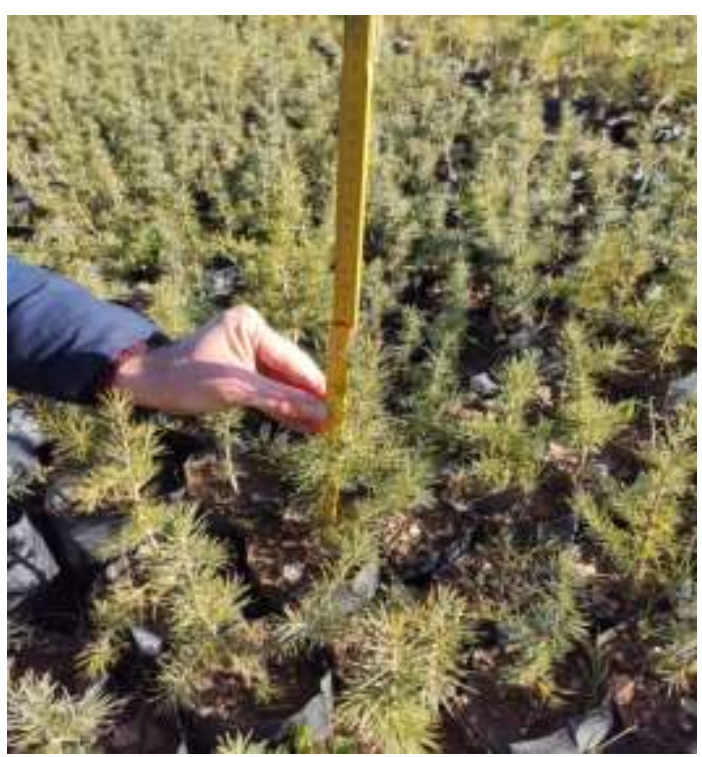

Şekil 2. Fidanlarda boy ve kök boğazı çapı ölçümü

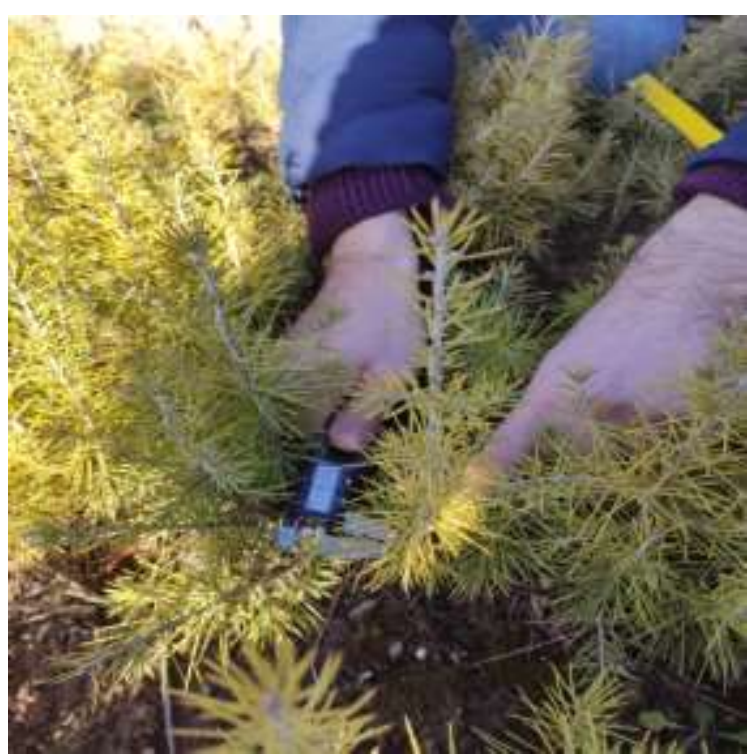

Türün 1+0 yaşlı tüplü fidanlarında, ortalama fidan boyu ve kök boğazı çapı, $13.1 \mathrm{~cm}$ ve $3.02 \mathrm{~mm}$ olarak belirlenirken; bu değerler çıplak köklü fidanlarında $6.2 \mathrm{~cm}$ ve $2.07 \mathrm{~mm}$ olarak belirlenmiştir (Çetinkaya ve Bilir 2019). Tunçtaner (1985) tarafından türün 5 fidanlık ve 2+0 yaşlı fidanlarında gerçekleştirilen bir çalışmada ortalama fidan boylarının fidanlıklarda 7.6-23.6 cm arasında değiştiği belirlenirken, bir fidanlıkta ölçülen ortalama kök boğazı çapı ise $3.2 \mathrm{~mm}$ olarak hesaplanmıştır. Ancak, gerek çalışmaya konu Toros sedirinde ve gerekse diğer orman ağacı türlerinde gerçekleştirilen çalışmalarda, fidan morfoloji ve kalitesine fidanlık koşulları, fidanlık uygulamaları, ekim sıklığı, orijin, tohum kaynağı gibi birçok çevresel ve biyolojik koşulların etkili olduğu bilinmektedir (Genç 1995, Demirci ve Bilir 2001, Yıldız 2005, Ivetić ve Škorić 2013, Bilir ve Çetinkaya 2018, Eser ve Gülcü 2019). Bu çalışmalardan örneğin Bilir ve Çetinkaya (2018), türün 1+0 yaşlı tüplü fidanlarının, çıplak köklü fidanlara oranla boy ve kök boğazı çapı bakımından daha yüksek gelişim performansı gösterdiğini belirlemişlerdir. Tohum kaynağı ve fidan tipi ile morfolojik fidan özelliklerine ilişkin benzer etkileşimler Kızılçam'da (Pinus brutia Ten.) da belirlenmiştir (Bilir 2019). Doğu Ladini (Picea orientalis (L.) Link.) üzerinde gerçekleştirilen bir başka çalışmada ise, şaşırtma zamanının fidan morfolojisi üzerinde etkili olduğu ifade edilmiştir (Genç 1995).

Varyasyon katsayısı (\%CV) değerleri her iki işlemde de fidan boyunda, kök boğazı çapına oranla daha yüksek çıkmıştır (Çizelge 2). 
Çizelge 2. İşlemlere göre fidan boyu ve kök boğazı çapı için varyasyon katsayısı (\%CV) ortalama değerler

\begin{tabular}{cccccccc}
\hline Özellik & \multicolumn{2}{c}{ ŞT (1+1) } & \multicolumn{2}{c}{ ÇK (2+0) } & \multicolumn{2}{c}{ Genel } \\
& Ortalama & CV & Ortalama & CV & Ortalama & CV \\
\hline FB (cm) & 17.51 & 26.86 & 15.09 & 19.74 & 16.30 & 25.15 \\
KBÇ (mm) & 5.33 & 18.98 & 3.67 & 16.26 & 4.50 & 25.98 \\
\hline
\end{tabular}

Fidan boyu ve kök boğazı çapı bakımından işlem içi ve işlemler arası farklılıklar uygulanan varyans analizi sonuçları ile de desteklenmiş olup, gerek işlemler arası ve gerekse işlem içi fidan kalite sınıfları arasında, istatistiksel bakımdan anlamlı $(p \leq 0.05)$ farklılıklar bulunmuştur (Çizelge 3).

TSE fidan kalite sınıflarına göre (Anonim 1988), kök boğazı çapı bakımından fidanların tamamı her iki işlemde de kaliteli fidan sınıfında yer almıştır. Ancak mevcut TSE fidan kalite sınıflarına (Anonim 1988) göre, fidanların yaş ve ağaç türü ile fidan tipine bakılmaksızın bütün fidanlar için kök boğazı çapı değerinin $2 \mathrm{~mm}$ olması ön görülmektedir. Ancak, kök boğazı çapı üzerine ağaç türü, fidan yaşı, fidanın çıplak köklü ya da kaplı oluşu gibi birçok faktör etkili olabilmektedir. Toros sedirinin $2+0$ yaşı fidanları üzerinde gerçekleştirilen çalışmada, kalite kriterleri olarak fidan boyu ve kök boğazı çapı esas kullanılmış ve KBÇ bakımından $6 \mathrm{~mm}$ 'den fazla olan fidanlar iyi kalitede, 4-6 mm arasında olanlar orta kaliteli ve $4 \mathrm{~mm}$ 'den kısa olan fidanlar ise fena kaliteli olarak sınıflandırımıştır. Ayrıca, bu sınıflandırmalar arazi denemeleri ile de desteklenmiştir (Eler ve ark. 1993).

Fidan boyu bakımından ise şaşırtma uygulanmış fidanların $\% 82$ 'si 1 . sınıfta ve $\% 18$ 'i 2 . sınıfta yer alırken, şaşırtma uygulanmamış fidanlarda 1 sınıf, 2. sınıf ve dikime elverişsiz fidan oranları $\% 86, \% 10$ ve $\% 4$ olarak sıralanmıştır. Fidan kalite sınıflarına göre fidan boyu ve kök boğazı çapı için ortalama değerler ile varyasyon katsayısı (\%CV) değerleri Çizelge 3'te verilmiştir. Çizelge 3'ten de görüldüğü üzere en yüksek ortalama fidan boyu $(18.3 \mathrm{~cm})$ ve kök boğazı çapı $(5.52 \mathrm{~mm})$ değerleri şaşırtılmış ve 1. sınıf fidanlarda; en düşük ise şaşırtılmamış fidanlarda ve sırasıyla, $9.40 \mathrm{~cm}$ ve $3.06 \mathrm{~mm}$ bulunmuştur. Eler ve ark. (1993) tarafından 2+0 yaşlı Toros sediri fidanları üzerinde gerçekleştirilen çalışmada da boy bakımından; $24 \mathrm{~cm}$ 'den daha uzun olan fidanlar iyi kaliteli, $16 \mathrm{~cm}$ 'den kısa fidanlar ise fena kaliteli olarak sınıflandırılmıştır. Ancak bu çalışmamızda elde edilen değerler farklı şaşırtma zamanı, süresi gibi nedenlere göre değişim gösterebilir. Zira, türün ağaçlandırma uygulamalarında genel olarak iki yaşlı (Anonim 1986) fidanları kullanılmaktadır ve çalışmada kullanılan şaşırtılmış fidanlarda şaşırtma uygulaması ilk büyüme dönemi sonunda gerçekleştirmiş olup, buna bağlı olarak fidan gelişiminde şaşırtma şokunun etkili olması kaçınılmazdır. Genç (1995), Doğu ladini üzerinde gerçekleştirmiş olduğu çalışmasında da, şaşırtma zamanının fidan kalitesini olumlu etkilediğini ortaya çıkarmıştır.

Çizelge 3. Kalite sınıflarına göre varyasyon katsayısı (\%CV) ve ortalama fidan boyu, kök boğazı çapı değerleri

\begin{tabular}{|c|c|c|c|c|c|c|c|c|}
\hline \multirow[b]{3}{*}{ Kalite sınıfı } & \multicolumn{4}{|c|}{ ŞT (1+1) } & \multicolumn{4}{|c|}{ ÇK (2+0) } \\
\hline & \multicolumn{2}{|c|}{ FB } & \multicolumn{2}{|c|}{ KBÇ } & \multicolumn{2}{|c|}{ FB } & \multicolumn{2}{|c|}{ KBÇ } \\
\hline & Ortalama* & CV & Ortalama & CV & Ortalama & CV & Ortalama & CV \\
\hline I. sınıf & $18.93^{b}$ & 20.82 & $5.52^{c}$ & 16.23 & $15.81^{b}$ & 15.97 & $3.66^{\mathrm{ab}}$ & 15.87 \\
\hline II. sınıf & $11.04^{a}$ & 5.08 & $4.43^{b}$ & 23.97 & $11.18^{\mathrm{a}}$ & 7.44 & $4.02^{\mathrm{b}}$ & 17.07 \\
\hline Elverişsiz & - & - & - & - & $9.40^{\mathrm{a}}$ & 6.01 & $3.06^{a}$ & 5.98 \\
\hline
\end{tabular}

*; Aynı harfler benzer grupları göstermektedir.

Varyans analizi sonucunda, fidan kalite sınıfları arasında istatistiksel bakımdan anlamlı $(p \leq 0.05)$ farklılık bulunmasıyla uygulanan Duncan testine göre, fidan boyu bakımından şaşırtılmış ve şaşırtılmamış 1 . sınıf fidanlar aynı grupta yer alırken; işlemlerde diğer kalite sınıflarına ait fidanlar farklı grup oluşturmuştur (Çizelge 3 ).
TSE fidan kalite sınıflarının (Anonim 1988), çalışmaya konu fidanlara uygunluğunun denetlenmesi amacıyla gerçekleştirilen Ayırma (Diskriminant) analizi sonucunda, fidan boyu bakımından TSE kalite sınıflarının, şaşırtılmış fidanlar için \%98, şaşırtılmamış fidanlar için \%92 ve her iki işlem için ise \%69 oranında başarılı olduğu belirlenmiştir. Her iki işlemde de kök boğazı çapı bakımından, fidanların 
tamamı kaliteli fidan sınıfında yer aldığından Ayırma analizi uygulanamamıştır. Ayırma analizi sonucu TSE fidan kalite sınıflarının (Anonim 1988), her iki işlemin ortak değerlendirilmesinde en düşük başarı (\%69) oranına sahip oluşu, TSE fidan kalite sınıflarının, fidan tipine bakılmaksızın türün bütün fidanları için ortak bir kalite sınıfı düzenlenmesinden kaynaklandığını düşündürmektedir. Toros sediri üzerinde yapılan çalışmalarda da fidan tipinin fidan kalitesi üzerine etkili olduğu ve tüplü fidanların çıplak köklü fidanlara oranla daha kaliteli fidanlara sahip olduğu belirlenmiştir (Bilir ve Çetinkaya 2018, Çetinkaya ve Bilir 2019).

Uygulanan korelasyon analizi sonucunda şaşırtılmış fidanlar ( $r=0.592)$ ile işlemlerin tamamında $(r=0.520$, Şekil $3)$, fidan boyu ile kök boğazı çapı arasında istatistiksel bakımdan anlamlı ( $p \leq 0.05)$ pozitif ilişkiler belirlenirken, şaşırtılmamış fidanlarda bunun tersi $(p>0.05)$ ortaya çıkmıştır.

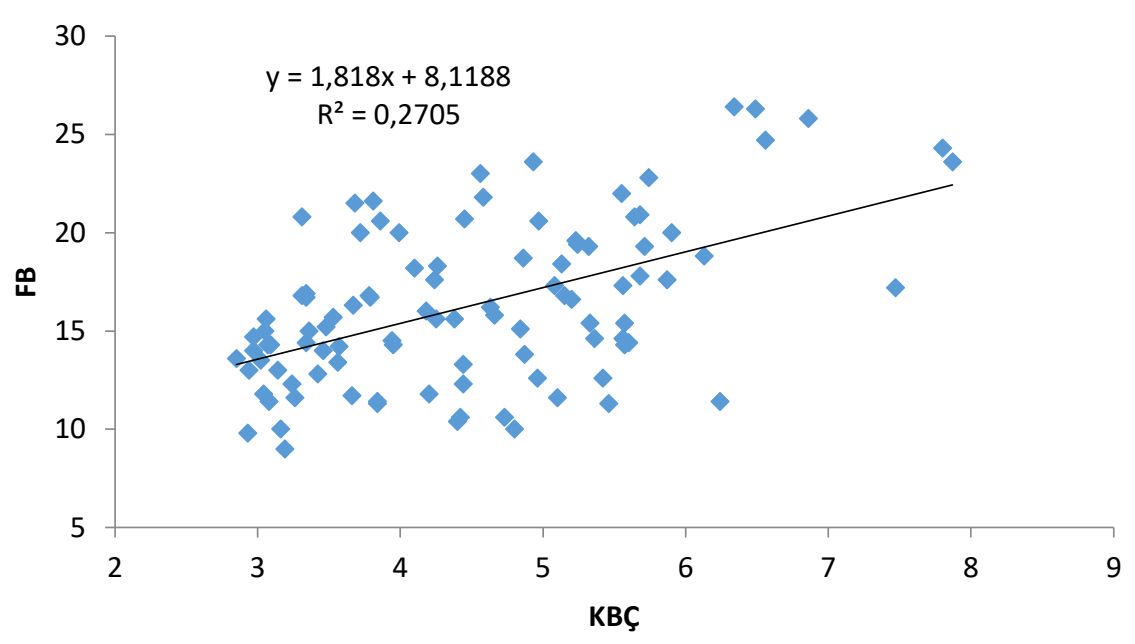

Şekil 3. Fidanlarda boy ve kök boğazı çapı ilişkisi

Fidan boyu ile kök boğazı çapı arasında istatistiksel bakımdan anlamlı $(p \leq 0.05)$ pozitif ilişkiler, tür üzerinde gerçekleştirilen diğer çalışmalarda da belirlenmiştir (Bilir ve Çetinkaya 2018, Çetinkaya ve Bilir 2019).

\section{SONUÇ}

Eğirdir Orman Fidanlığında yetiştirilen $1+1$ yaşı şaşırtılmış tüplü ve şaşırtılmamış $2+0$ yaşlı çıplak köklü Toros sediri fidanları üzerinde gerçekleştirilen ve fidan morfoloji ve kalitesine yönelik bu çalışma sonucunda:

Şaşırtılmış ve şaşırtılmamış fidanlarda, ortalama fidan boyu $16.30 \mathrm{~cm}$, kök boğazı çapı ise $4.50 \mathrm{~mm}$ bulunmuş olup bu değerler sırasıyla şaşırtılmış fidanlarda $17.51 \mathrm{~cm}$ ve $5.33 \mathrm{~mm}$, şaşırtılmamış fidanlarda ise $15.09 \mathrm{~cm}$ ve 3.67 $\mathrm{mm}$ bulunmuştur. Ancak bu çalışma tek tohum kaynağı ve vejetasyon dönemi sonunda şaşırtılan fidanlar üzerinde gerçekleştirilmiştir. Bu nedenle şaşırtmanın fidan morfolojisine olan etkisinin daha net belirlenebilmesi amacıyla farklı tohum kaynakları ve değişik şaşırtma zamanına yönelik yeni çalışmalar gerçekleştirilmelidir.
TSE fidan kalite sınıflarına göre, kök boğazı çapı bakımından şaşırtıımış ve şaşırtılmamış fidanların tamamı kaliteli fidan sınıfında yer almıştır. Fidan boyu bakımından ise şaşırtma uygulanmış fidanların \%82'si 1 . sınıfta, şaşırtma uygulanmamış fidanların ise \%86'sı 1 . sınıfta yer alırken, dikime elverişsiz fidan sadece \%4 ile şaşırtılmamış fidanlarda yer almıştır. TSE fidan kalite sınıflarının şaşırtılmış fidanlar için \% 98 , şaşırtılmamış fidanlar için \%92 ve her iki işlem için ise \%69 oranında başarılı olduğu belirlenmiştir. Bu sonuçlar türde yaş ve fidan tipine göre yeni kalite sınıfı intiyacını da vurgulamaktadır.

Fidan boyu ile kök boğazı çapı arasında istatistiksel bakımdan anlamlı $(p \leq 0.05)$ pozitif ilişkiler türün seyreltme gibi fidanlık uygulamaları için önemlidir.

\section{TEŞEKKÜR}

Çalışmama katkılarından dolayı, Eğirdir Orman Fidanlığı yönetim ve çalışanları ile veri toplama sırasındaki desteklerinde dolayı Öğr. Gör. Samet DiRLik'e teşekkür ederim. 


\section{KAYNAKLAR}

Anonim (1988) İğne yapraklı ağaç fidanları, TS 2265/Şubat-1988. Türk Standartları Enstitüsü yayınları, Ankara.

Anonim (1986) Fidanlık Çalışmaları. Orman Genel Müdürlüğü Yayınları, Ankara.

Ayan S, Yer EN, Gülseven O (2017) Türkiye'deki Toros sediri (Cedrus libani A. Rich.) ağaçlandırma sahalarının iklim tipi açısından değerlendirilmesi. Artvin Çoruh Üniversitesi Orman Fakültesi Dergisi 18 (2):152-161.

Aydeniz A (1985) Toprak Amenajmanı. Ankara Üniversitesi, Ziraat Fakültesi Yayınları, Ankara

Bilir N, Çetinkaya D (2018) Variation of morphology and quality in $1+0$ year containerized and bare-root seedlings of Taurus Cedar (Cedrus libani A. Rich.). 4th International Conference Reforestation Challenges, p. 10, 19-23 June, Belgrade, Serbia.

Bilir N (2019) Kızılçam'da (Pinus brutia Ten.) fidan kalitesi. Mehmet Akif Ersoy Üniversitesi Fen Bilimleri Enstitüsü Dergisi 10(1):95101.

Boydak M, Çalıkoğlu M (2008) Toros Sedirinin (Cedrus libani A.Rich.) biyolojisi ve silvikültürü. Orman Genel Müdülüğü Yayınları, Ankara.

Çatal YA (2002) Toros sediri (Cedrus libani A. Rich. )'nde yetiştirme sıklığının bazı morfolojik fidan özelliklerine etkisi. Süleyman Demirel Üniversitesi, Fen Bilimleri Enstitüsü. Yüksek Lisans Tezi.

Çetinkaya D, Bilir N (2019) Toros sediri'nde (Cedrus libani A. Rich.) fidan tipi $x$ fidan morfolojisi etkileşimi. Mehmet Akif Ersoy Üniversitesi Fen Bilimleri Enstitüsü Dergisi 10(1):28-33.

De Martonne E (1942) Nouvelle carte modiale de l'indice d'aridit é. Annaes de Géographie, 51:242- 250.

Demirci A, Bilir N (2001) Yaşı 3-0 olan Toros sediri (Cedrus libani A. Rich.) fidanlarında orijinler arası farklılıklar. Turkish Journal of Agriculture and Forestry 25:217-223.
Eler Ü, Keskin S, Örtel E (1993) Toros sediri (Cedrus libani A. Rich.) fidanlarında kalite sınıflarının belirlenmesi üzerine araştırmalar. Ormancılık Araştırma Enstitüsü Dergisi 240:81-105.

Erinç S (1965) Yağış müessiriyeti üzerine bir deneme ve yeni bir indis. İstanbul Üniversitesi, Coğrafya Enstitüsü, 41.

Eser Y, Gülcü S (2019) The effects of growing density and fertilization on morphological seedling characteristics of crimean juniper (Juniperus excelsa Bieb.). Turkish Journal of Forestry, 20(1): 1519.

Genç M (1995) Doğu ladini (Picea orientalis (L.) Link.)'nde şaşırtmafidan morfolojik özellikleri etkileşimleri. İstanbul Üniversitesi Orman Fakültesi Dergisi 45 (1):107-119.

Güner ŞT, Güner D, Şahin U (2018) Toros sedirinde yetiştirme sıklığının fidan morfolojik özellikleri ve beslenme durumuna etkisi. Ormancılık Araştırma Dergisi, 5 (1):44-55.

Ivetić V, Škorić M (2013) The impact of seeds provenance and nursery production method on Austrian pine (Pinus nigra Arn.) seedlings quality. Ann. For. Res. 56(2):297-305.

Kayadibi B (2011) Toros sedirinin fidanlıkta yetiştirilmesinde seyreltme ve kök kesimi işlemlerinin etkisi. Artvin Çoruh Üniversitesi, FBE. Yüksek Lisans Tezi.

Orman Genel Müdürlüğü (2020a) Ormancılık istatistikleri-2019. www.ogm.gov.tr, Ankara.

Orman Genel Müdürlüğü (2020b) Ormancılık haberleri. www.ogm.gov.tr, Ankara.

Tunçtaner İA (1985) Bazı fidanlıklarımızdaki çeşitli ibreli fidanların kaliteleri ile fidanlarla topraktan tüketilen bazı besin maddeleri ve gübreleme. Orman Mühendisliği Dergisi 22(12):27-35.

Yer EN, Ayan S (2011) Eskişehir orman fidanlığı koşullarında yetiştirilen çıplak köklü Toros sediri ve Anadolu karaçamı fidanlarının gelişim dönemleri. Kastamonu Üniversitesi, Orman Fakültesi Dergisi 11(2):219-227.

Yıldız D (2005) Bazı yetiştirme tekniklerinin Toros sediri (Cedrus libani A. Rich.)'nde fidan morfolojisine etkisi. Süleyman Demirel Üniversitesi, FBE. Yüksek Lisans Tezi. 